\title{
Neuroscan of Normal and
} Abnormal Vertebrae and Spinal Cord

\author{
${ }^{1}$ Ritsuko K Pooh, ${ }^{2}$ Asim Kurjak \\ ${ }^{1}$ CRIFM Clinical Research Institute of Fetal Medicine, Osaka, Japan \\ ${ }^{2}$ Department of Obstetrics and Gynecology, Medical School University of Zagreb, Sveti Duh Hospital, Zagreb, Croatia \\ Correspondence: Ritsuko K Pooh, Clinical Research Institute of Fetal Medicine \\ PMC, 3-7, Uehommachi 7, Tennoji, Osaka \#543-0001, Japan, e-mail: rkpooh@guitar.ocn.ne.jp
}

\begin{abstract}
The vertebral body, neural arch and its processes develop from the sclerotome of the primitive mesodermal segments. After chondrification, separate ossification centres appear for the body and one for each of the neural arches. Vertebrae are composed of a body and a vertebral arch. The vertebral foramina, which consist of the vertebral arch and back of vertebral body, form the vertebral canal including and protecting the spinal cord. The vertebral arches are formed by two pedicles and two laminae which unite as a spinous process.

Relation between the vertebrae and spinal cord during pregnancy is interesting. In embryonal period, the CNS develops earlier than other part of embryonal structures and occupies approximately one third of the whole embryonal body. At the 3rd month of development the length of the spinal cord equals that of the vertebral column. The spinal nerves and the relationship of the spinal nerves to the vertebra are established. Therefore the spinal cord segment is at the same level as the corresponding vertebral level. In subsequent fetal period, however, fetal body structure including vertebral column develops faster than the neural tube. As the consequence of this different development of the column and nerves, caudal end of the spinal cord within the vertebral column relatively moves upward with advancing gestation and reaches to the level of the third lumber vertebra at birth.
\end{abstract}

Keywords: Neuroscan of normal and abnormal vertebra, spinal development, spina bifida.

\section{NORMAL VERTEBRAL AND SPINAL DEVELOPMENT}

Reports of sonographic studies have been published over a decade. Sonographic demonstration of the origin of the three ossification centers as one at each lamina-pedicle junction and one in the vertebral body was reported in 1988, using waterbath and a specimen of vertebral column removed from a 17week stillborn fetus. ${ }^{1}$ In 1991, sonographic evaluation of the neural arch ossification centers of the distal fetal spine in 239 fetuses was reported. ${ }^{2}$ They described that ossification of the neural arch centers occurred in a predictable pattern and in a caudal direction and that an additional vertebral level became ossified every 2-3 weeks from L-5 and, S-2 was ossified by 22 weeks.
Demonstration of spinal/vertebral structures by using 3D ultrasound has been reported from 1996. ${ }^{3-6}$

Figure 1 shows the neural tube in a 6-week-embryo (crown lump length of $5.5 \mathrm{~mm}$ ) and spinal cord in 8 and 9-week-fetus detected by 3D ultrasound. Figure 2 shows three orthogonal view and 3D reconstructed image of normal fetus at 16 weeks of gestation. Movement of region of interest provides 3D reconstruction image of the surface level, neural arch level and vertebral body level. Figure 3 shows the changing appearance of vertebral bony structure between 9 and 22 weeks of gestation. By 13 weeks of gestation, vertebral bodies and intervertebral spaces and bilateral premature vertebral arches are clearly demonstrated. Until 15 weeks of gestation, bilateral laminae are completely apart at all vertebral levels and this condition is so-called "physiological spina bifida". At lumbosacral level, a distance of the median opening between bilateral arches is wider than at thoracic level. At 16 and 17 weeks, the right and left laminae grow toward a median line and closely approach each other at thoracic level but still clearly separate at lumbosacral

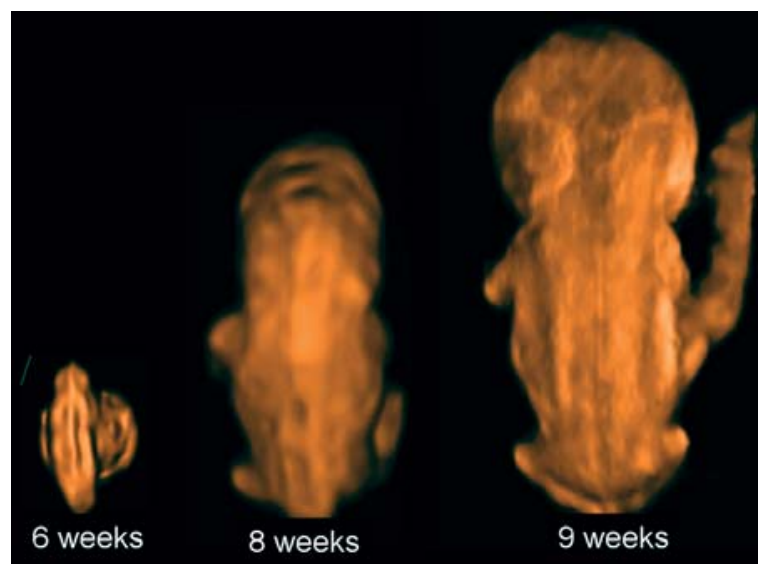

Fig. 1: 3D reconstructed image of the embryo (6 to 9 weeks of gestation). Embryonal sizes are $5.5 \mathrm{~mm}, 18.3 \mathrm{~mm}$ and $26.3 \mathrm{~mm}$. At 9 weeks of gestation, the spinal cord is demonstrated as a thin line, compared with that at 8 weeks of gestation 


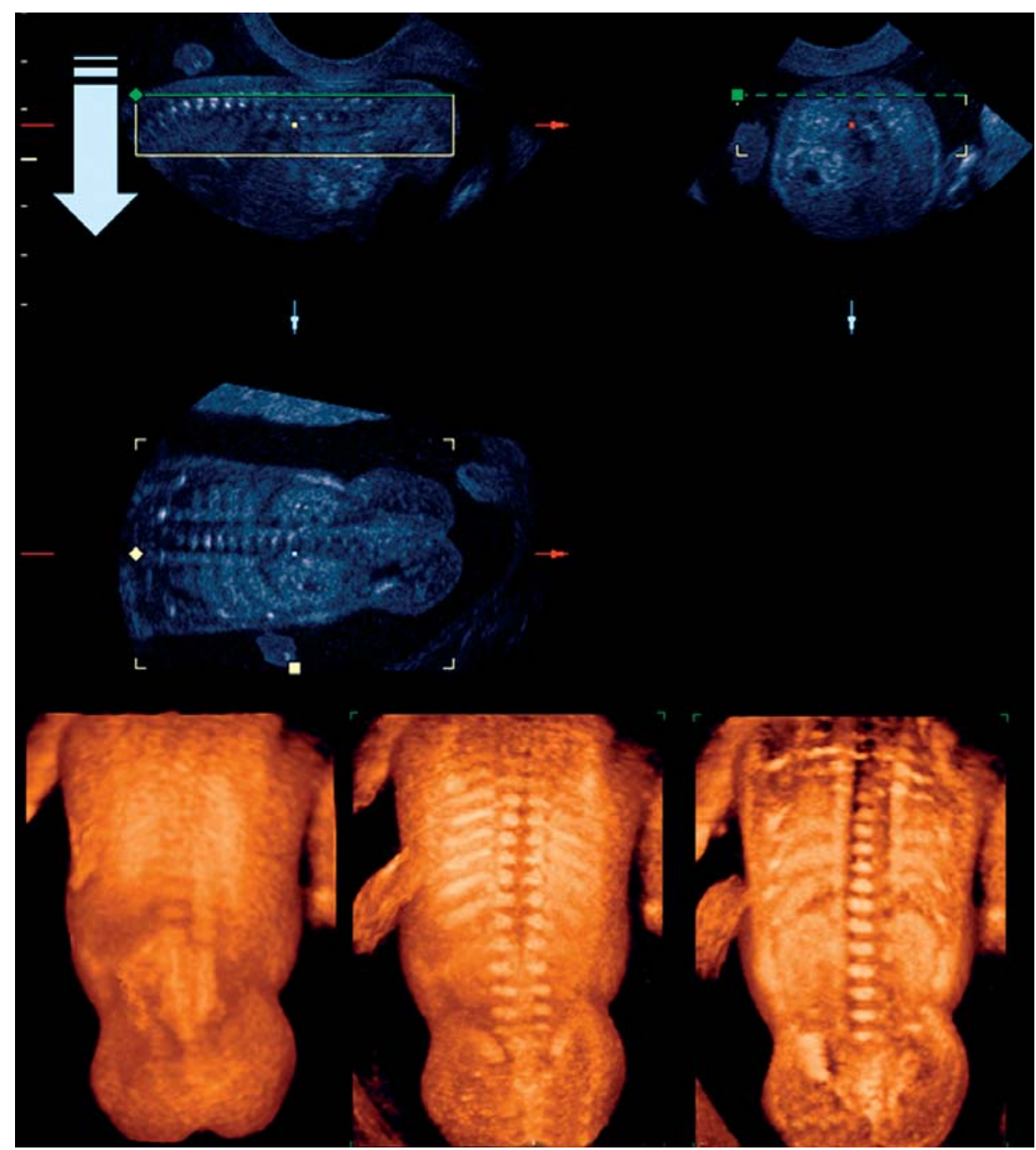

Fig. 2: Three orthogonal view and 3D reconstructed image of normal fetus at 16 weeks of gestation. 3D ultrasound shows vertebral laminae (lower middle), vertebral bodies and intervertebral disc spaces (lower right)

level, and thereafter, gradual approach is seen. At 18 and 19 weeks, lumbosacral vertebral laminae still separate each other in a median line, but before 23 weeks of gestation, gaps between bilateral laminae at lumbosacral levels are almost closed. Postanterior sagittal view by transabdominal scan is favorable for vertebral screening scan (Fig. 4).

\section{NEURAL TUBE DEFECT (SPINA BIFIDA)}

Spina bifida aperta, manifest form of spina bifida is classified into 4 types: meningocele, myelomeningocele, myelocystocele, myeloschisis. In myelomeningocele the spinal cord and its protective covering (the meninges) protrude from an opening in the spine. In meningocele, the spinal cord develops normally but the meninges protrude from a spinal opening. The most common location of the malformations is the lumber and sacral areas of the spinal cord.

\section{Prevalence}

0.7-2 / 1000 births but certain populations have a significantly greater risk. Many reported remarkable reduction of prevalence of NTDs after using folic acid supplementation and fortification. ${ }^{7-10}$

\section{Etiology}

Multifactorial inheritance, single mutant genes, autosomal recessive, chromosomal abnormalities (trisomy 18, 13), specific teratogens (valproic acid), maternal diabetes, environmental factors, predominant in females.

\section{Pathogenesis}

Failure of the neural arch fusion, which occurs most frequently in the lumbar region results in a condition known as spina bifida. In embryonal period by four weeks, closure of the rostral and 

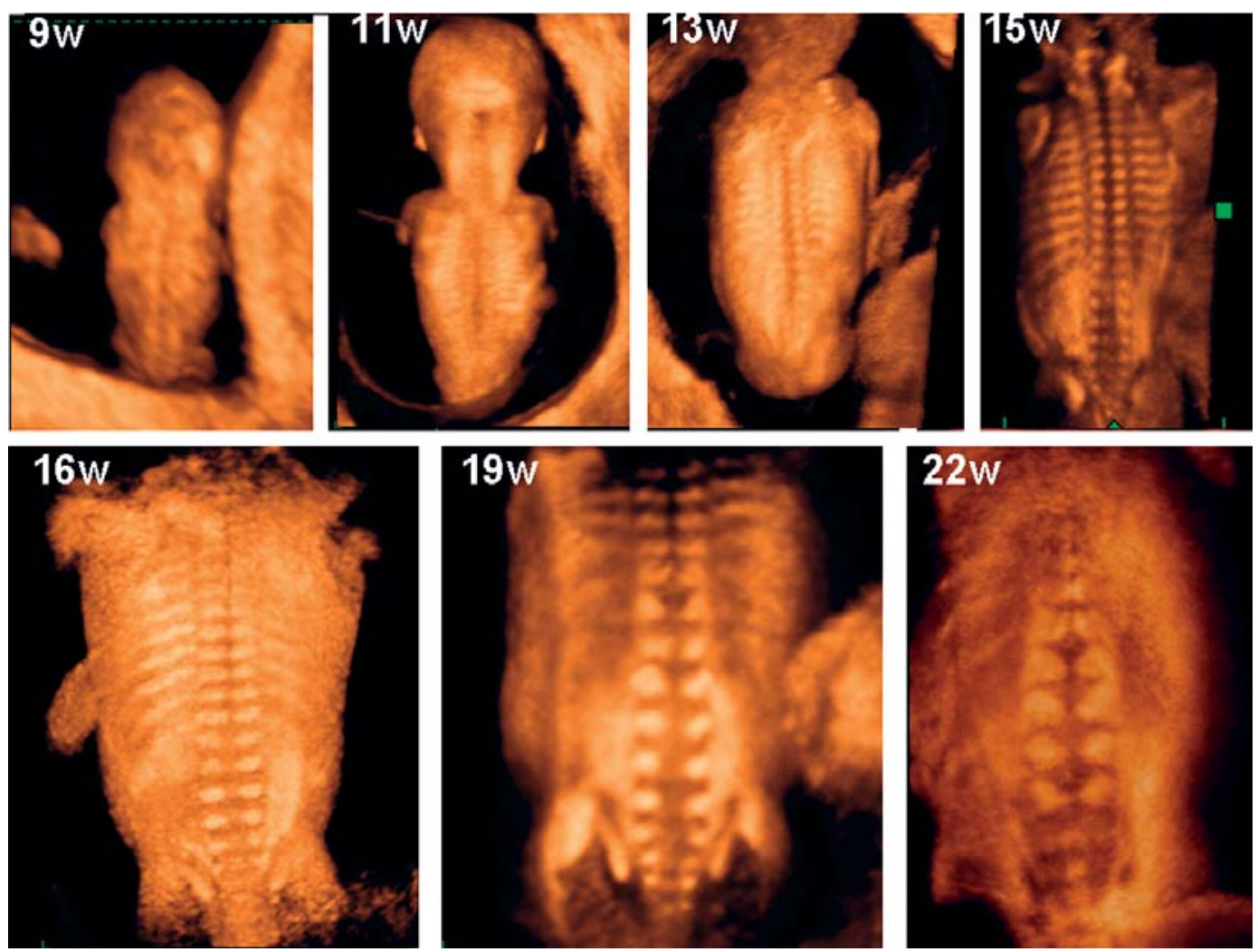

Fig. 3: Fetal vertebral development by 3D US from 9 to 22 weeks of gestation. Approaching stage of bilateral vertebral lamina according to neural tube closure is visible with advanced gestational weeks
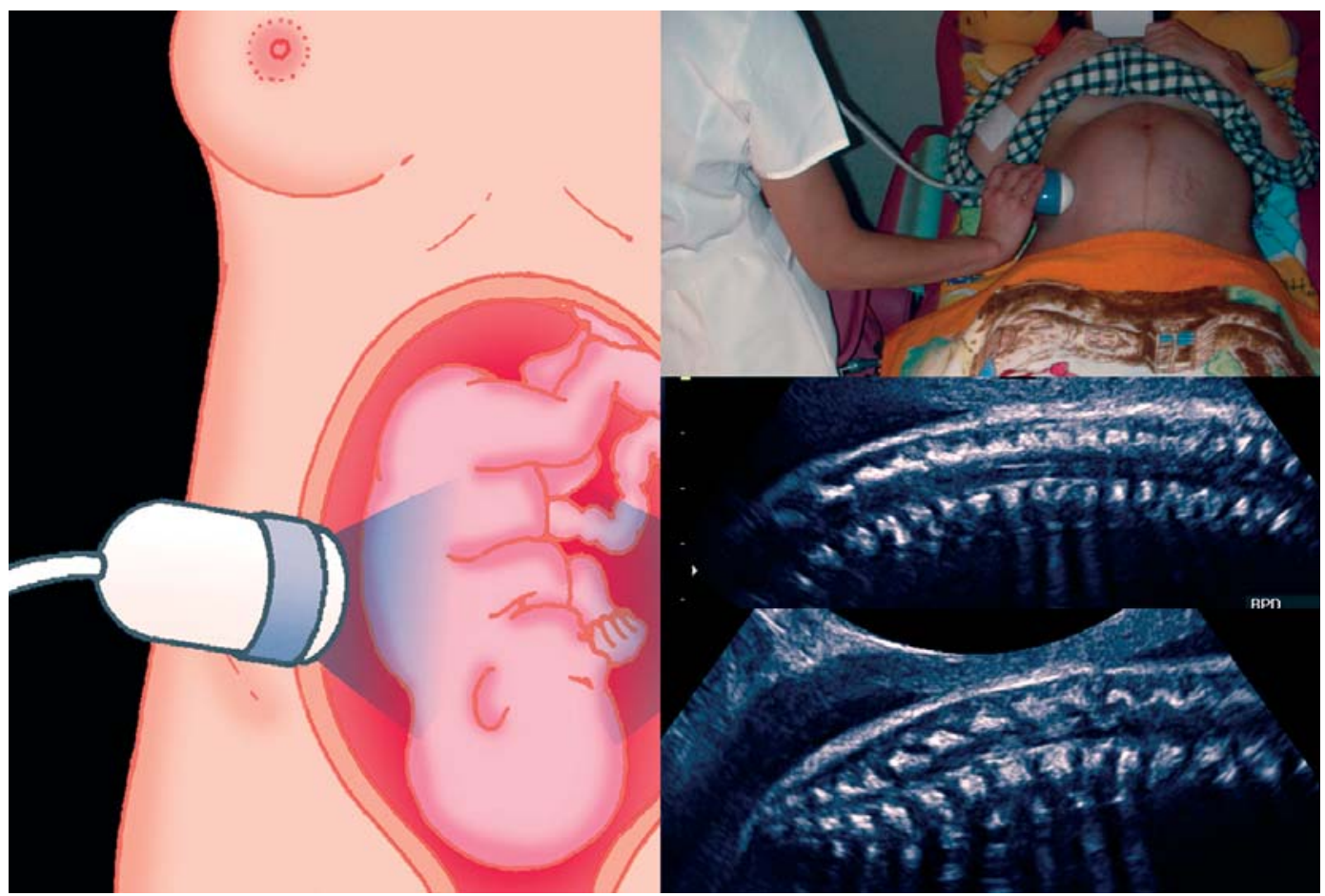

Fig. 4: Postanterior sagittal view by transabdominal scan is favorable for vertebral screening scan 
caudal neuropores occurs. There are two theories in etiology; primary failure of neural tube closure and rupture of a previously closed neural tube due to overdistension.

\section{Associated Anomalies}

Chiari type II malformation, ventriculomegaly or hydrocephalus in $88 \%$ of cases with open spina bifida, ${ }^{11}$ scoliosis (above L2), kyphosis, polyhydramnios, additional non-CNS anomalies.

\section{Prenatal Diagnosis}

It was reported in 1992 that sonographic lesion level and pathologic level were in agreement in $64 \%$ of cases with spina bifida and were within one spinal level in $79 \%$ and they concluded that ultrasonography allow accurate prediction of the spina bifida lesion level and neuromotor handicap. ${ }^{12}$

Recent advanced 3D technology with higher resolutional imaging, has contributed to more comprehensive and precise evaluation of the spine and vertebra. Three cases of spina bifida at as early as nine weeks of gestation detected by $2 \mathrm{D}$ and $3 \mathrm{D}$ ultrasound with additional tomograms reported..$^{13}$ The level of the defect on 3D images are more informative for localizing bony defects of the fetal spine. ${ }^{14}$ Transvaginal 3D sonographic approach is useful for screening and evaluation of fetal spinal/ vertebral lesions in the first half of pregnancy. ${ }^{15,16}$ Early detection of the spina bifida in the first trimester is shown in Figure 5 and anencephaly in Figure 6. Surface anatomy of the fetus and appearance of clubfoot (Fig. 7), which occasionally manifests from middle gestation, and ankle joint deformity (Fig. 8) are understandable by using 3D ultrasound. 3D ultrasound with maximum mode can demonstrate bony structure such as kyphosis (Fig. 9) and is helpful to detect the spinal levels of lesion and to predict neurological prognosis. Occasionally diastematomyelia (split cord) can be detected (Fig. 10). Figures 11 and 12 show myeloschisis in the second and third trimesters. Because more than $80 \%$ of cases with open spina bifida, ventriculomegaly is apparent during pregnancy due to Chiari type II malformation (Fig. 11), spina bifida is detected in many cases, following demonstration of
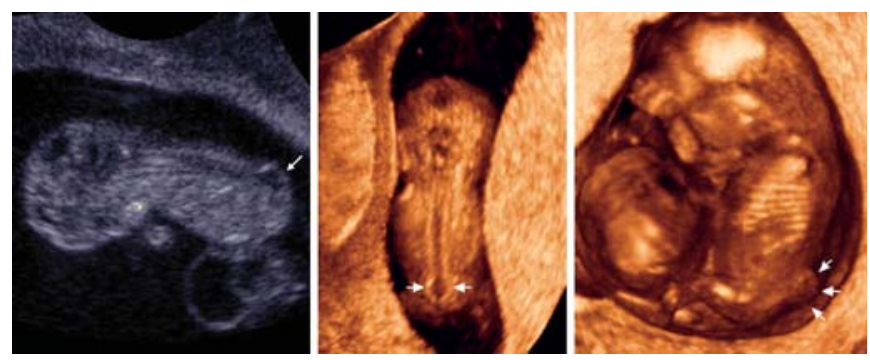

Fig. 5: Myelomeningocele in the first trimester. Two dimensional US (left) and three dimensional dorsal view (middle) at 9 weeks clearly demonstrate a neural tube defect at the lower lumber level (arrows). Right figure shows the same fetus at 12 weeks of gestation. Arrows indicate the lumber myelomeningocele

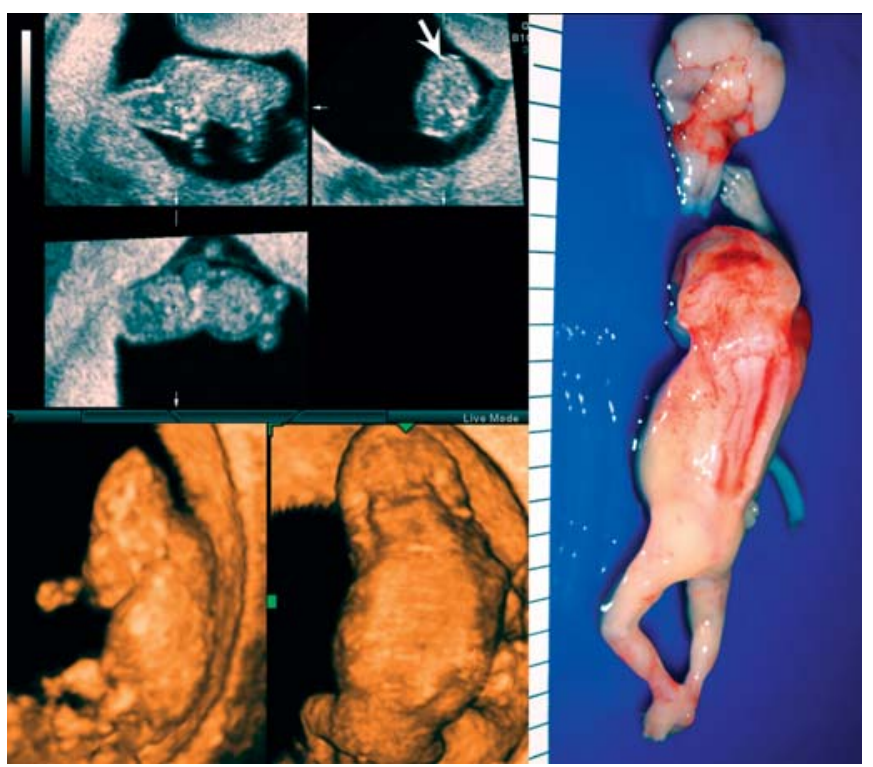

Fig. 6: Iniencephaly and acrania at 10 weeks of gestation. (Upper left) Three orthogonal view of the fetus. Spina bifida (arrow) was demonstrated in the coronal section. (Lower left and middle) 3D images shows the fetal lateral and dorsal views. (Right) external appearance of aborted fetus. The brain and a part of spinal cord was detached at delivery
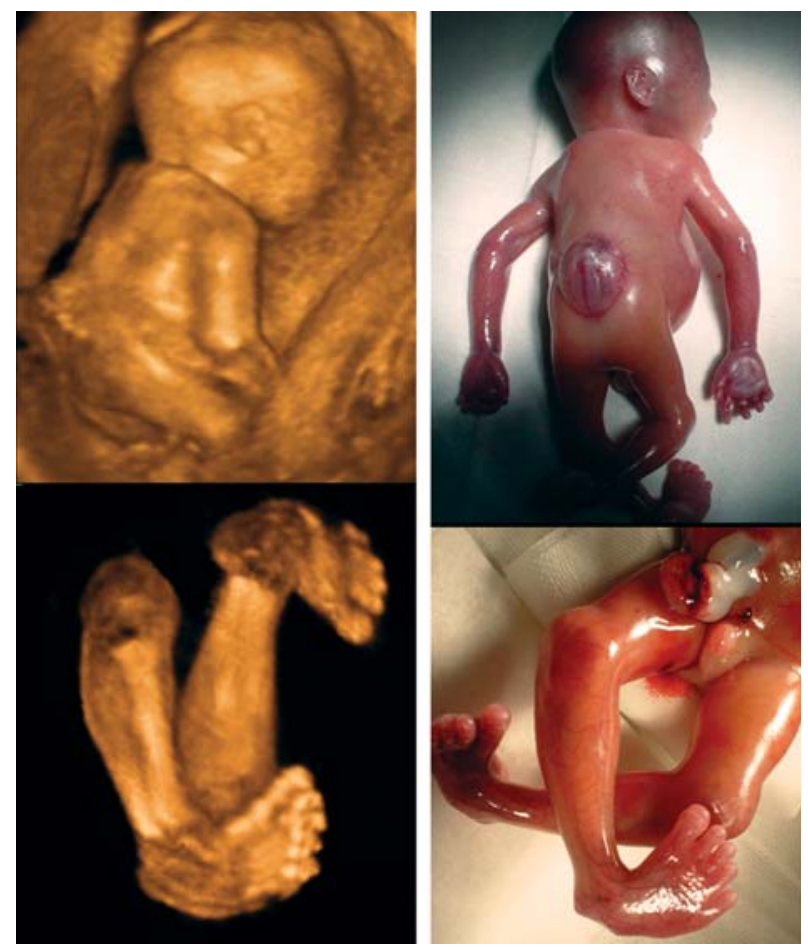

Fig. 7: Myelomeningocele with clubfoot. (Upper left) 3D image of the fetus with myelomeningocele with kyphosis at 20 weeks of gestation. (Upper right) macroscopic picture of aborted fetus at 21 weeks. Huge myelomengocele is visualized. (Lower left) 3D image of the fetal legs. Severe clubfoot is demonstrated. (lower right) appearance of lower extremities after termination of pregnancy 

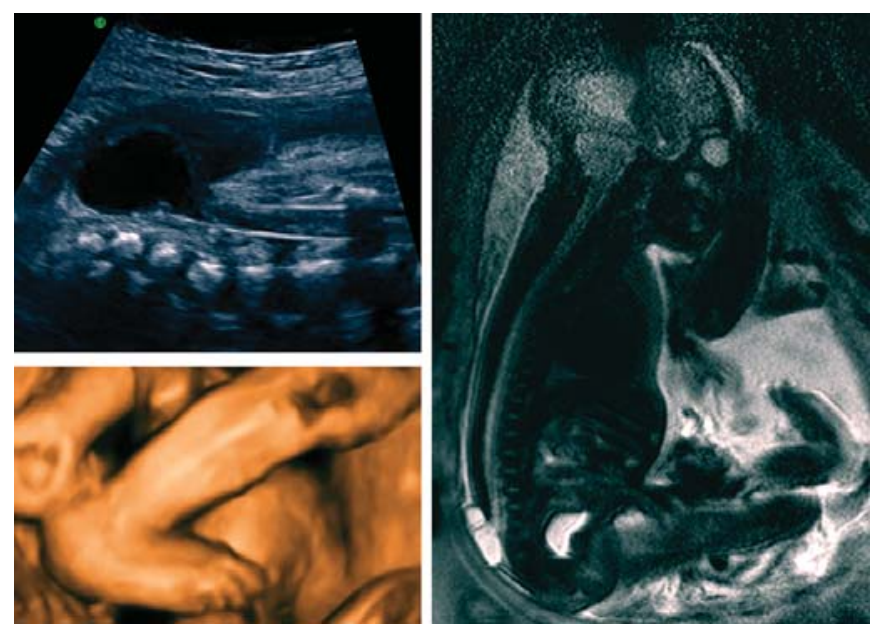

Fig. 8: Myelomeningocele and ankle joint deformity at 37 weeks. (Upper left) 2D ultrasound image of myelomeningocele. (Lower left) 3D ultrasound image of ankle joint. (Right) fetal MRI

ventriculomegaly. In cases of meningocele, spinal cord is located in the spinal canal (Fig. 13).

\section{Differential Diagnosis}

Sacrococcygeal teratoma (Fig. 14), which develops at the base of the coccyx (tailbone) in 1 in every 35,000 live births, and is the most common tumor in the newborn.

\section{Prognosis}

Disturbance of moter, sensory and sphincter function. Depends on lesion levels. Below S1; enable to walk unaided, above L2; wheelchair dependant, variable at intermediate level. Menkes
JH et al summarized relations among the lesion level, primary neurologic deficits and functional disability. Spinal lesion over L3 may strongly lead to nonambulatory, abnormal skin sensation, and no bowel and bladder control. Infants with lesion of L4 or below, may ambulate with aids, braces or by orthopedic surgery with abnormal skin sensation and variable levels of incontinence. Infants with lesion of S1 or below, may ambulate with minimal aid. Thus, assessment of spinal lesion level directly leads to estimation of postnatal neurological deficit and potential future capacities. ${ }^{17}$ Biggio JR et al clinically studied to resolve whether prenatal ultrasound findings predict ambulatory status with open spina bifida. According to their results, lower (more caudal) lesion levels and smaller ventricular size were associated with ambulatory status, no infant with a thoracic lesion was ambulatory, while all infants with L4-sacral lesions were ambulatory and infants with L1-L3 lesions, 50\% were ambulatory, and no infant with a myeloschisis was ambulatory. They concluded that sonographic determination of lesion level and type is useful in predicting the ambulatory potential of fetuses with open spina bifida. ${ }^{18}$

\section{Recurrence Risk}

Decreased, almost no recurrence rate by use of folic acid supplementation and fortification. ${ }^{19}$

\section{Obstetrical Management}

Delivery mode is controversial. Cesarean delivery has been advocated as being superior to vaginal delivery in preventing further neurologic damage in fetuses with antenatally diagnosed myelomeningocele. ${ }^{20}$ However, there has been the data showing no difference of motor function or ambulation status when stratified by route of delivery. ${ }^{21,22}$
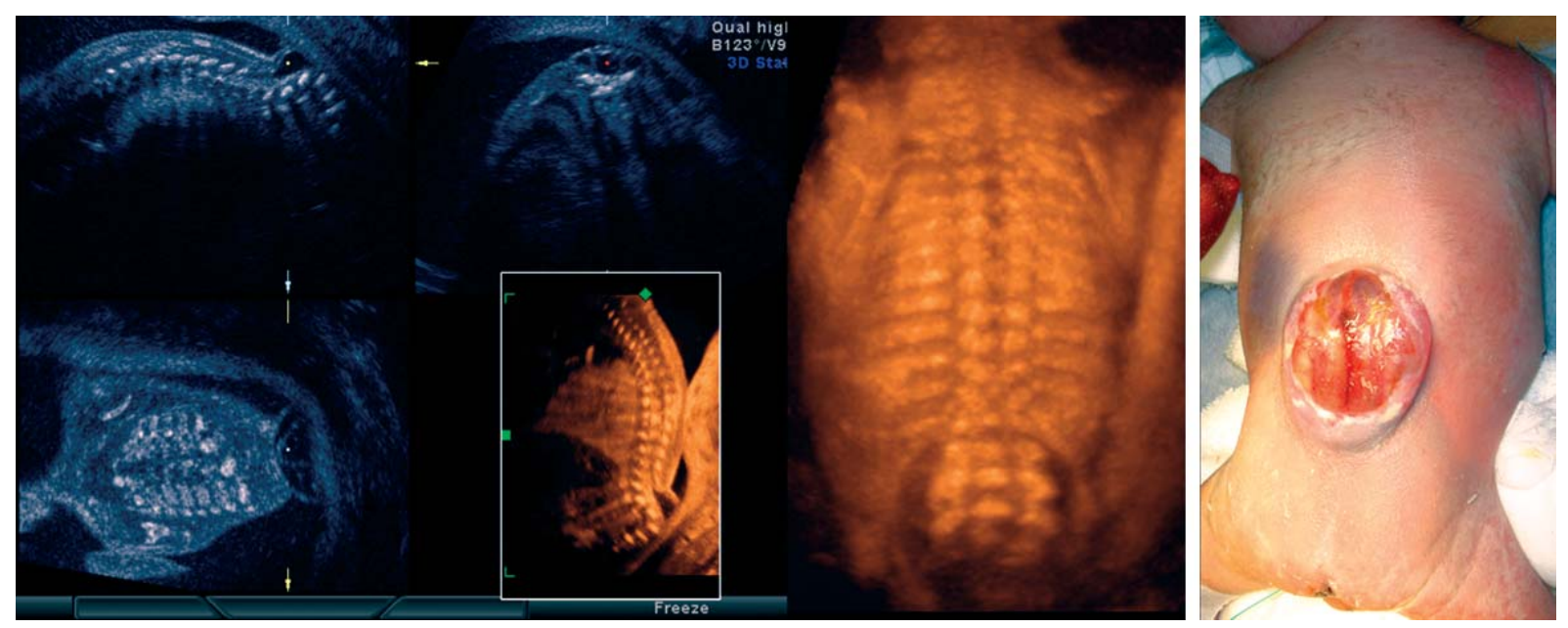

Fig. 9: Myelomeningocele with severe kyphosis detected at 20 weeks of gestation. (Left) Black-white pictures show three orthogonal view of vertebral structure and myelomeningocele with severe kyphosis. 3D reconstruction bony structure in the sagittal section clearly demonstrated the vertebral bodies. (Middle) 3D surface reconstruction image of fetal back shows the large myelomeningocele from T12. (Right) macroscopic picture of the same baby born at 37 weeks 

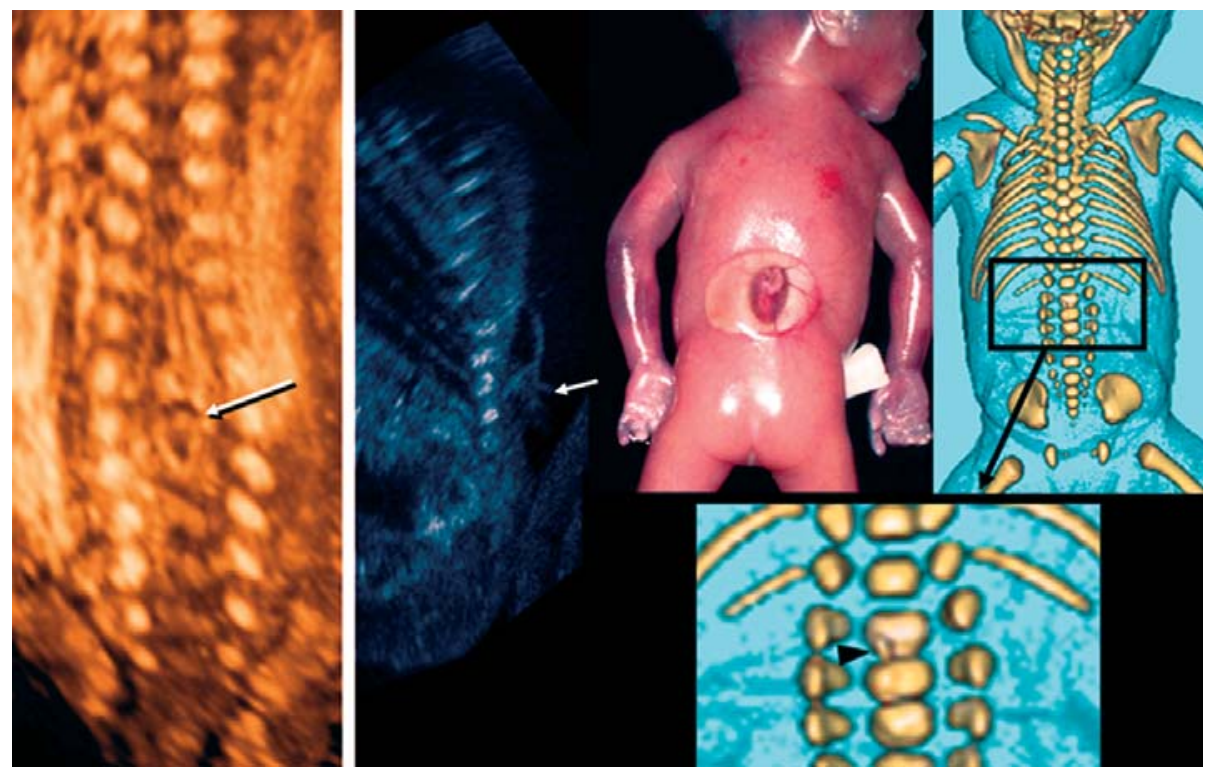

Fig. 10: Diastematomyelia at 15 weeks. (Left) 3D ultrasound at 15 weeks. Arrow indicates split cord. (Middle) sagittal image from orthogonal view. Rupture of myelomingocele is demonstrated (arrow). (Right) aborted fetus at 21 weeks and postmortem 3D-CT images which show clearly bony structure. Arrowhead indicates small cartilage spur from vertebral body, which makes spinal cord split and may be a cause of rupture of myelomeningocele
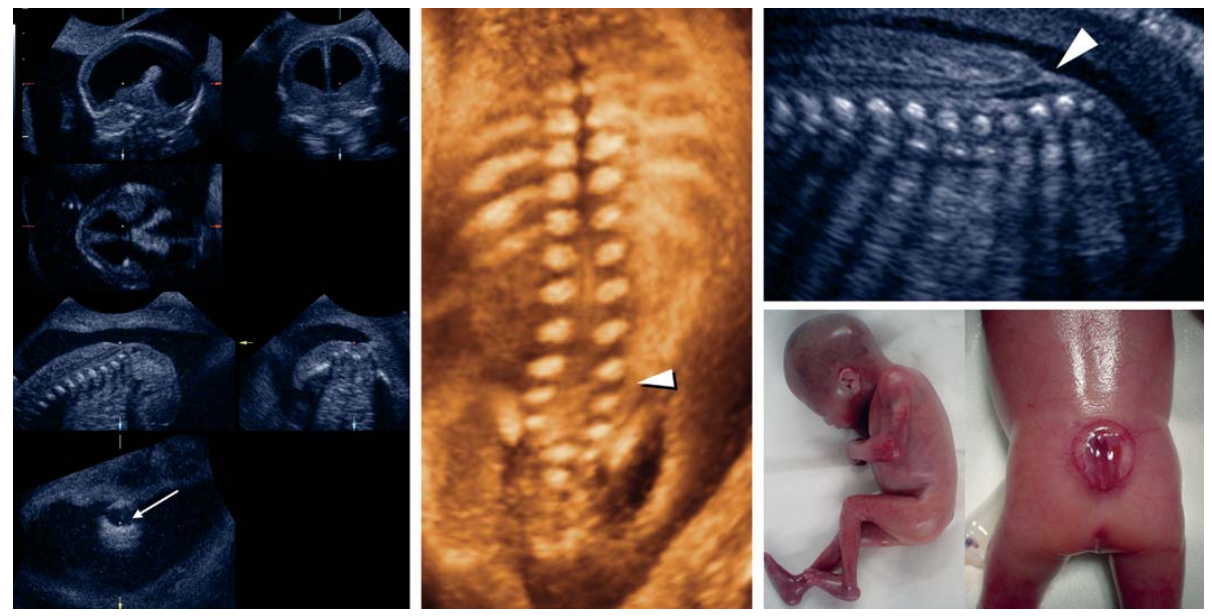

Fig. 11: Myeloschisis detected at 18 weeks of gestation. (Left) black-white pictures show three orthogonal view of vertebral structure and myeloschisis. It is difficult to detect myeloschisis because no cyst-or meningocele is formed. Arrow indicates skin defect of lesion. 3D reconstruction bony structure shows lumbosacral spina bifida (arrowhead). (Upper right) mid sagittal section of the spine. The spinal cord runs from spinal tube to directly the surface of fetal back (arrowhead). (Lower right) macroscopic findings of aborted fetus at 21 weeks of gestation. The lesion, not demonstrated on the lateral view, is clearly visible on the posterior view

\section{Neurosurgical Management \\ Spina Bifida Aperta}

In cases with defect of normal skin tissue, immediate closure of spina bifida after birth reduces spinal infection. Spinal cord reconstruction is the most important role of operation. Miniature Ommaya reservoir placement and subsequent ventriculo- peritoneal shunt are required for hydrocephalus. For symptomatic Chiari malformation, posterior fossa decompressive craniectomy and/or tonsillectomy is performed.

\section{Spina Bifida Occulta}

The aim of surgical treatment for is decompression of the spinal cord and cutting off tethering to the spinal cord. 

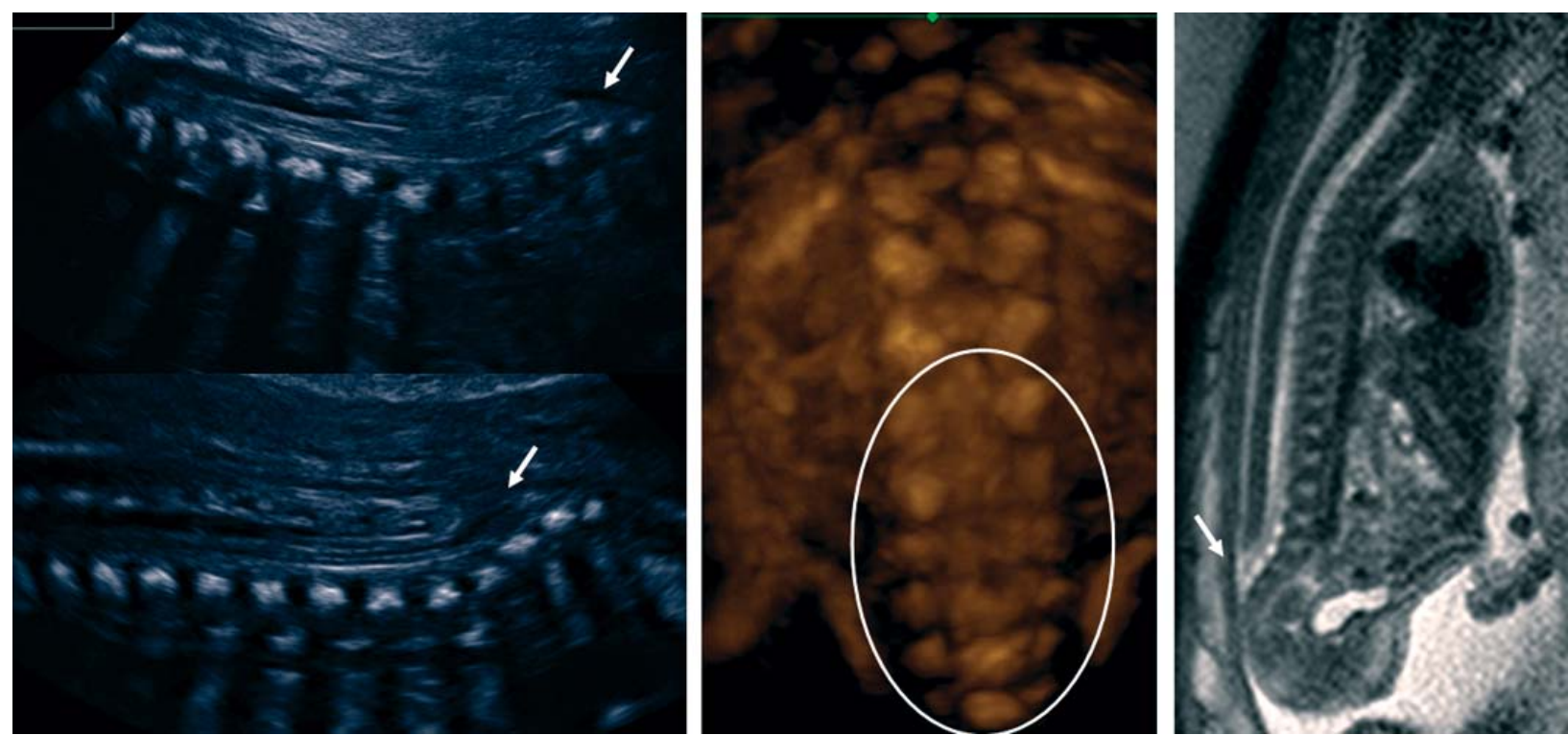

Fig. 12: Myeloschisis detected at 22 weeks of gestation. (Left) 2D ultrasound images of myeloschisis. Arrows indicate spinal cord on the fetal surface. (Middle) 3D ultrasound image of lumber vertebrae. Circle indicates spina bifida. (Right) fetal MRI
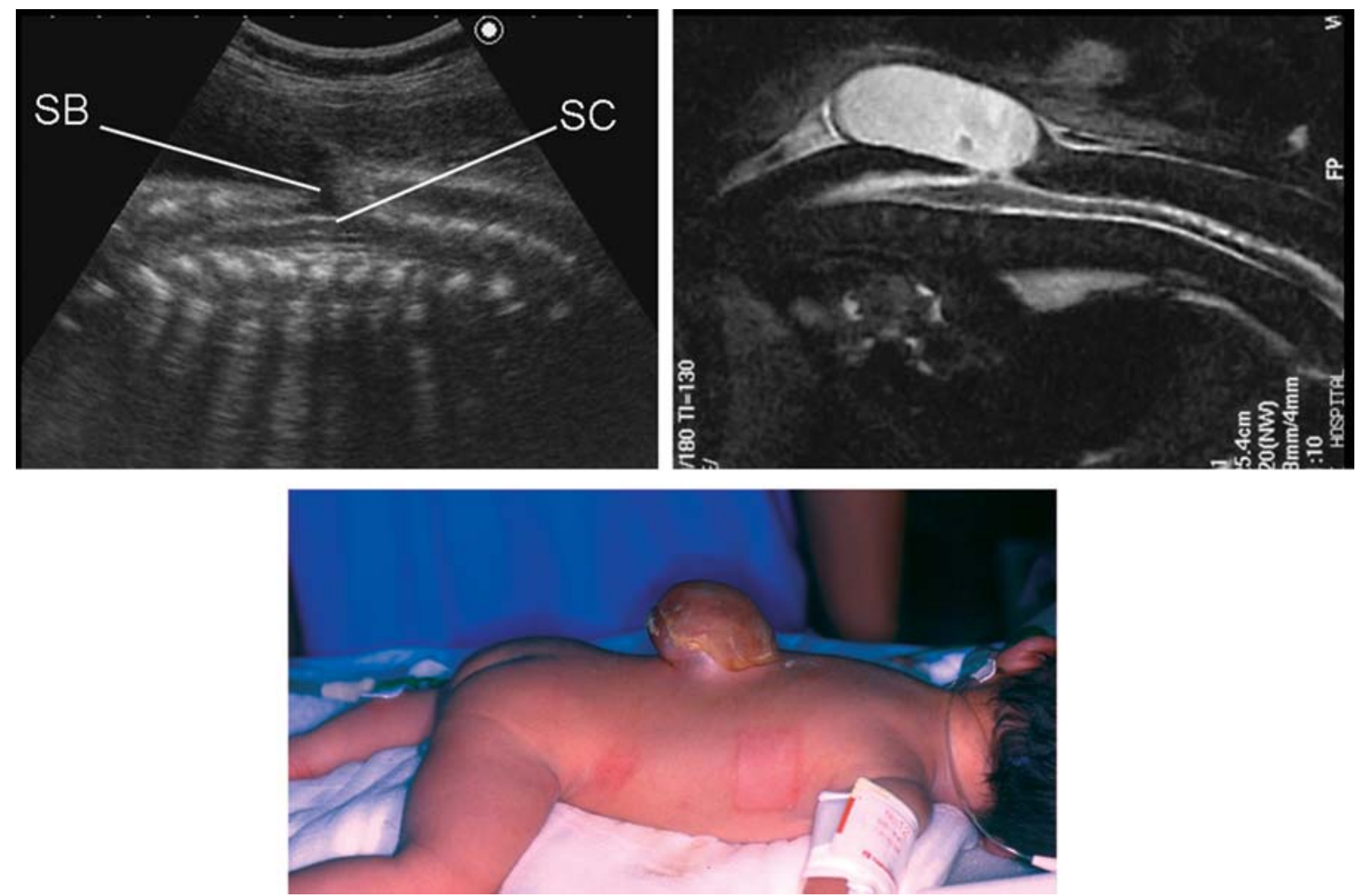

Fig. 13: Thoracic meningocele. (Upper left) sagittal US image at 37 weeks of gestation. Spinal cord (SC) is located inside of the spinal canal. Spina bifida (SB) is demonstrated. (Upper right) fetal MR sagittal image. The meninges protrude from a spinal opening and form meningocele. (Lower) postnatal appearance of meningocele, which is completely covered by skin 

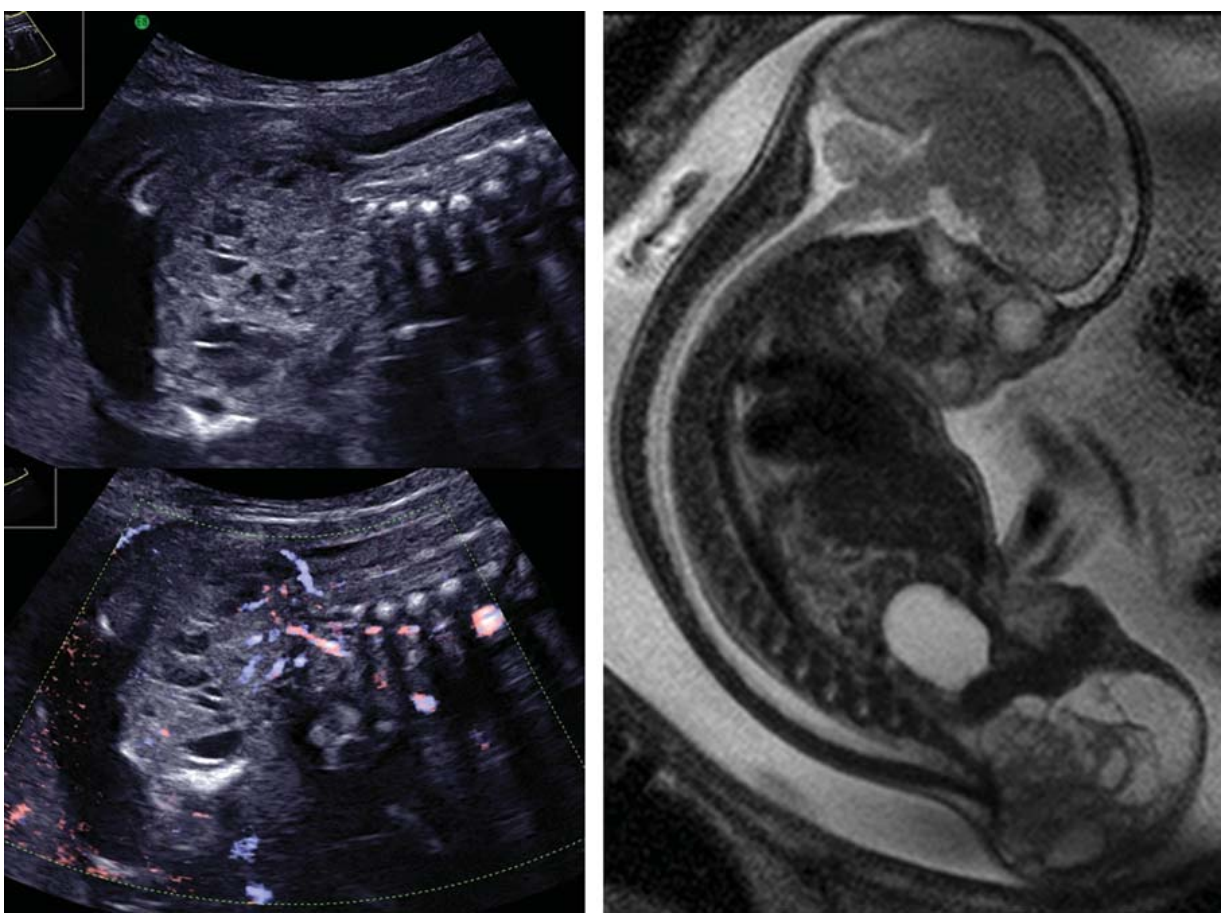

Fig. 14: Sacrococcygeal teratoma at 26 weeks. 2D ultrasound image (left upper) and power Doppler image (left lower). Right figure shows fetal MRI. Both US and MR images show intact spinal cord, separate from teratoma

\section{OTHER VERTEBRAL ABNORMALITIES}

\section{Syringomyelia}

Syringomyelia is the development of a fluid-filled cavity or syrinx within the spinal cord.

\section{Prevalence}

Fetal syringomyelia is rare.

\section{Etiology}

Craniovertebral junction abnormalities, including small posterior fossa, cerebellar tonsils and vermis herniation, Chiari malformation, membranous abnormalities.

\section{Pathogenesis}

Many mechanisms for syrinx formation have been postulated, the exact pathogenesis is still unknown.

\section{Associated Anomalies}

Chiari malformation.

\section{Prenatal Diagnosis}

Figure 15 shows fetal syringomyelia by MRI in a case of myelomeningocele and Chiari type II malformation.
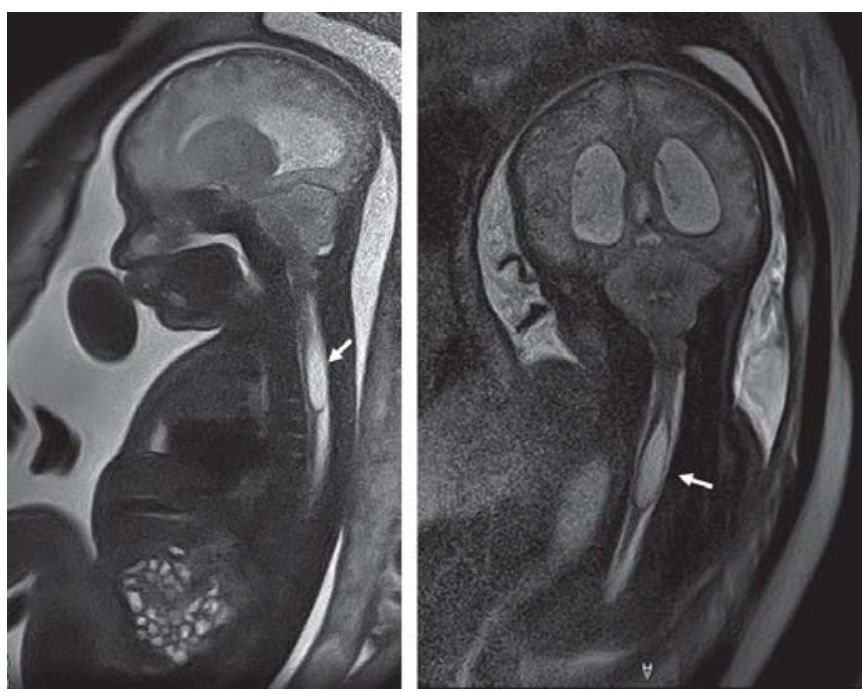

Fig. 15: Fetal syringomyelia by MRI in a case of myelomeningocele and Chiari type II malformation. Sagittal image (left) and coronal image (right). Arrows indicate syringomyelia

\section{Treatment}

Surgery is not always recommended for syringomyelia. When the cause of syringomyelia is Chiari malformation, occasionally foramen magnum decompression is performed. 


\section{Congenital Scoliosis}

\section{Definition}

Congenital scoliosis is a lateral curvature of the spine that is due to the presence of vertebral anomalies that cause an imbalance in the longitudinal growth of the spine. The congenital vertebral anomalies are classified based on failure of formation (hemivertebra), failure of segmentation (block vertebra or unilateral bar) and a combination of the two. The most common type of failure of formation anomaly is a hemivertebra. This is where a portion of the vertebra is missing resulting in a small, triangular shaped "half vertebra" or hemivertebra. ${ }^{23}$

\section{Prevalence}

Unknown. Often recognized at birth, more subtle spinal defects can remain undetected.

\section{Etiology}

Genetic or environmental etiology, but still unclear.

\section{Pathogenesis}

The spine is formed during a process called somitogenesis between 20 and 30 days of gestation. The somites are regularly sized and spaced and the segmentation is associated with drastic cellular cytoskeletal rearrangements and biomechanical changes. Disruption of somitogenesis resulted in congenital scoliosis.

\section{Associated Anomalies}

Absent ribs or fused ribs are common associated defect, since the ribs derive from the same embryonic origins as the vertebrae. Genitourinary system abnormality, including unilateral kidney, ureteric duplication or obstruction. ${ }^{24}$ Cardiac anomalies. ${ }^{25}$ Spinal cord abnormalities including tethered cord, fibrous dural bands, diastemetomyelia, or intradural lipoma. ${ }^{26}$

\section{Prenatal Diagnosis}

Figures 16 and 17 show fetuses with congenital scoliosis due to hemivertebrae, detected by 3D ultrasound.
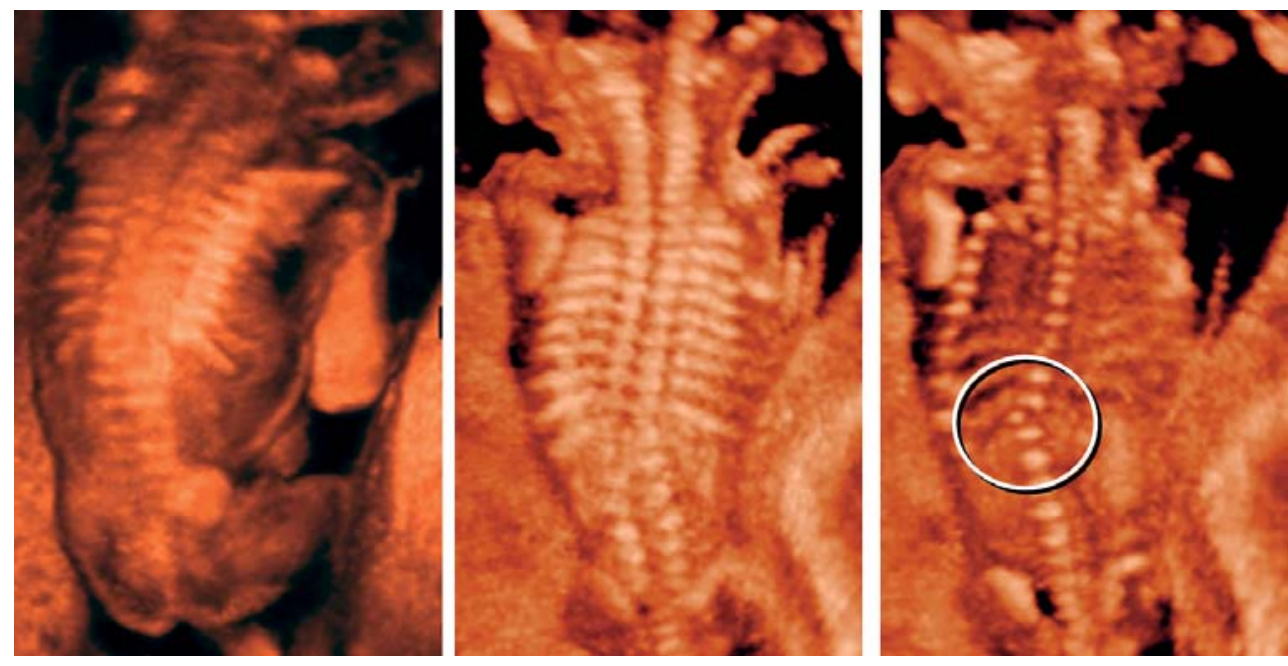

Fig. 16: Fetuses with congenital scoliosis due to hemivertebrae, detected by 3D ultrasound at 19 weeks. (Left) surface anatomy of scoliosis. (Middle) bony structure. Note the different number of bilateral ribs, 11 ribs in left and 10 in right. (Right) a circle shows hemivertebra of 12 th thoracic vertebral body which is a cause of scoliosis
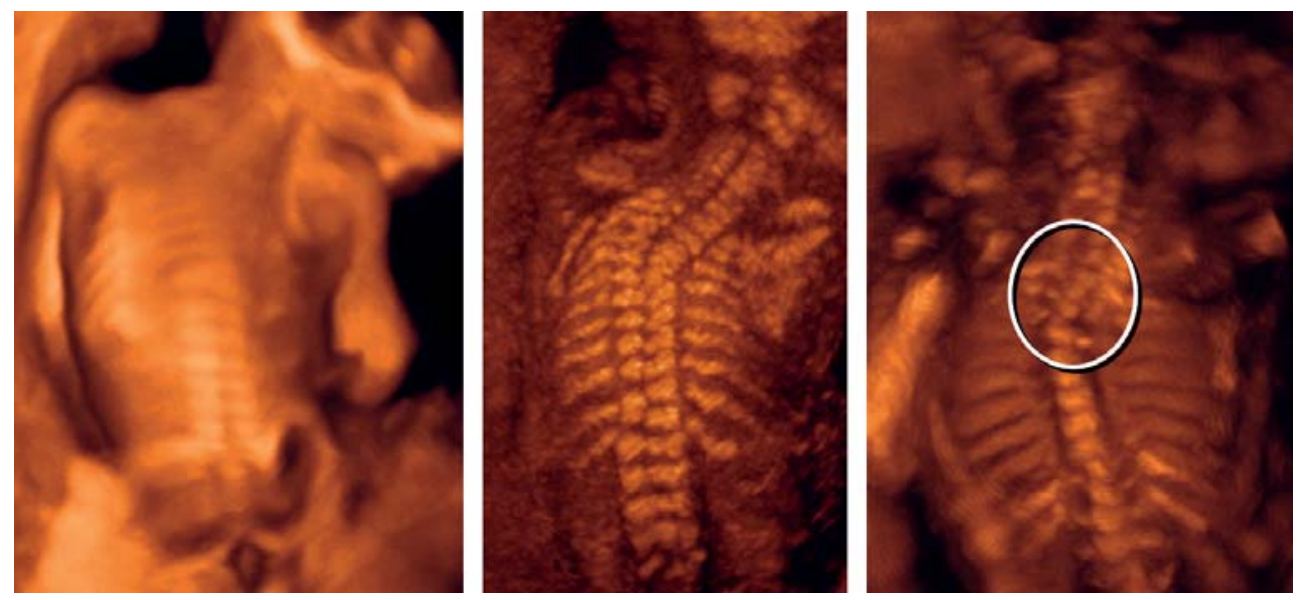

Fig. 17: Fetuses with congenital scoliosis due to hemivertebrae, detected by 3D ultrasound at 20 weeks. (Left) surface anatomy of scoliosis. (Middle) bony structure. Note the different number of bilateral ribs, 12 ribs in left and 9 in right. (Right) a circle shows hemivertebra of 2 nd to 4 th thoracic vertebral bodies which is a cause of scoliosis 


\section{Treatment}

Surgical treatment is planed depending on the progression of the spinal curvature.

\section{REFERENCES}

1. Gray DL, Crane JP, Rudloff MA. Prenatal diagnosis of neural tube defects: origin of midtrimester vertebral ossification centers as determined by sonographic water-bath studies. J Ultrasound Med 1988;7:421-27.

2. Budorick NE, Pretorius DH, Grafe MR, et al. Ossification of the fetal spine. Radiology 1991;181:561-65.

3. Riccabona M, Johnson D, Pretorius DH, et al. Three dimensional ultrasound: display modalities in the fetal spine and thorax. Eur J Radiol 1996;22:141-45.

4. Mueller GM, Weiner CP, Yankowitz J. Three-dimensional ultrasound in the evaluation of fetal head and spine anomalies. Obstet Gynecol 1996;88:372-78.

5. Johnson DD, Pretorius DH, Riccabona M, et al. Threedimensional ultrasound of the fetal spine. Obstet Gynecol 1997;89:434-38.

6. Dyson RL, Pretorius DH, Budorick NE, et al. Three-dimensional ultrasound in the evaluation of fetal anomalies. Ultrasound Obstet Gynecol 2000;16:321-28.

7. Martinez de Villarreal L, Perez JZ, Vazquez PA, Herrera RH, Campos Mdel R, Lopez RA, Ramirez JL, et al. Decline of neural tube defects cases after a folic acid campaign in Nuevo Leon, Mexico. Teratology 2002;66:249-56.

8. Ray JG, Meier C, Vermeulen MJ, Boss S, Wyatt PR, Cole DE. Association of neural tube defects and folic acid food fortification in Canada. Lancet 2002;360:2047-48.

9. Persad VL, Van den Hof MC, Dube JM, Zimmer P. Incidence of open neural tube defects in Nova Scotia after folic acid fortification. CMAJ 2002;167:241-45.

10. Mathews TJ, Honein MA, Erickson JD. Spina bifida and anencephaly prevalence-United States, 1991-2001. MMWR Recomm Rep 2002;51:9-11.

11. Biggio JR Jr, Wenstrom KD, Owen J. Fetal open spina bifida: a natural history of disease progression in utero. Prenat Diagn 2004;24:287-89.

12. Kollias SS, Goldstein RB, Cogen PH, Filly RA. Prenatally detected myelomeningoceles: sonographic accuracy in estimation of the spinal level. Radiology 1992;185:109-12.
13. Blaas HG, Eik-Nes SH, Isaksen CV. The detection of spina bifida before 10 gestational weeks using two- and three-dimensional ultrasound. Ultrasound Obstet Gynecol 2000;16:25-29.

14. Lee W, Chaiworapongsa T, Romero R, et al. A diagnostic approach for the evaluation of spina bifida by three-dimensional ultrasonography. J Ultrasound Med 2002;21:619-26.

15. Pooh RK, Pooh KH. Fetal neuroimaging with new technology. Ultrasound Review Obstet Gynecology 2002;2:178-181.

16. Pooh RK, Maeda K, Pooh KH. An Atlas of Fetal Central Nervous System Disease. Diagnosis and Management. Parthenon CRC Press, London, New York, 2003.

17. Menkes JH, Sarnat HB (Eds). Neuroembryology, genetic programming, and malformations. In Child Neurology (6th ed). Philadelphia, PA: Lippincott Williams and Wilkins; 2000:316.

18. Biggio JR, Owen J, Wenstrom KD, et al. Can prenatal ultrasound findings predict ambulatory status in fetuses with open spina bifida? Am J Obstet Gynecol 2001;185:1016-20.

19. Stevenson RE, Allen WP, Pai GS, Best R, Seaver LH, Dean J, Thompson S. Decline in prevalence of neural tube defects in a high-risk region of the United States Pediatrics 2000;106: 677-83.

20. Luthy DA, Wardinsky T, Shurtleff DB, Hollenbach KA, Hickok DE, Nyberg DA, et al. Cesarean section before the onset of labor and subsequent motor function in infants with meningomyelocele diagnosed antenatally. N Engl J Med 1991;324:662-66.

21. Merrill DC, Goodwin P, Burson JM, Sato Y, Williamson R, Weiner CP. The optimal route of delivery for fetal meningomyelocele. Am J Obstet Gynecol 1998;179:235-40.

22. Lewis D, Tolosa JE, Kaufmann M, Goodman M, Farrell C, Berghella V. Elective Cesarean Delivery and long-term Motor Function or Ambulation Status in Infants with Meningomyelocele. Obstet Gynecol 2004;103:469-73.

23. Erol B, Kusumi K, Lou BAJ, Dormans JP. Etiology of Congenital Scoliosis. UPOJ 2002;15: 37-42.

24. McMaster MJ. Congenital scoliosis caused by a unilateral failure of vertebral segmentation with contralateral hemivertebrae. Spine 1998;23:998-1005.

25. Rivard CH, Narbaitz R, Uhthoff HK. Time of induction of congenital vertebral malformations in human and mouse embryo. Orthop Rev 1979;8:135-39.

26. Murakami U, Kameyama Y. Vertebral malformations in the mouse fetus caused by maternal hypoxia during early stages of pregnancy. J Embryol Exp Morphol 1963;11:107-18. 